\title{
Epidemiologic Features of NSCLC Gene Alterations in Hispanic Patients from Puerto Rico
}

\author{
Ruifang Zheng ${ }^{1}$, Zhiwei Yin ${ }^{1}$, Albert Alhatem ${ }^{1}{ }^{\mathbb{D}}$, Derek Lyle ${ }^{2}$, Bei You ${ }^{1,3}$, Andrew S. Jiang ${ }^{4}$, \\ Dongfang Liu ${ }^{1}$, Zsolt Jobbagy ${ }^{1}$, Qing Wang ${ }^{1}$, Seena Aisner ${ }^{1}$ and Jie-Gen Jiang ${ }^{1,3, *}$ \\ 1 Department of Pathology, Immunology \& Laboratory Medicine, Rutgers New Jersey Medicine School, \\ Newark, NJ 07103, USA; zhengru@njms.rutgers.edu (R.Z.); yinz@mskcc.org (Z.Y.); \\ aa1919@njms.rutgers.edu (A.A.); yoube@njms.rutgers.edu (B.Y.); d1907@njms.rutgers.edu (D.L.); \\ zj89@njms.rutgers.edu (Z.J.); wangq3@njms.rutgers.edu (Q.W.); aisnersc@njms.rutgers.edu (S.A.) \\ 2 Genoptix Medical Laboratory, 2110 Rutherford Road, Carlsbad, CA 92008, USA; dlyle@genoptix.com \\ 3 The Genomics Center, Rutgers New Jersey Medical School, Newark, NJ 07103, USA \\ 4 College of Medicine, Drexel University, Philadelphia, PA 19129, USA; aj594@drexel.edu \\ * Correspondence: jj688@njms.rutgers.edu
}

Received: 6 October 2020; Accepted: 19 November 2020; Published: 24 November 2020

Simple Summary: We have analyzed the molecular genetic profiles of Hispanic non-small cell lung cancer (NSCLC) patients from Puerto Rico. In addition to the general characteristics, especially on EGFR mutations, we have also reported some novel findings on the incidences of KRAS mutation subgroups, other driver gene alterations, and passenger gene alterations, as well as KRAS/TP53 and KRAS/STK11 co-mutations. Moreover, our study has identified the FGFR2-TACC2 translocation in this population.

\begin{abstract}
Targeted therapy has changed the paradigm of advanced NSCLC management by improving the survival rate of patients carrying actionable gene alterations using specific inhibitors. The epidemiologic features of these alterations vary among races. Understanding the racial differences benefits drug development, clinical trial design, and health resource allocation. Compared to Caucasian and Asian populations, current knowledge on Hispanic patients is less and no data of Hispanic patients from Puerto Rico have been reported. We retrieved and analyzed the demographic, clinical, and molecular data of Hispanic NSCLC patients from Puerto Rico with molecular tests performed in the Genoptix Medical Laboratory in Carlsbad, CA, USA between 2011 and 2018. The majority of the NSCLC patients in our study had either adenocarcinoma $(75.4 \%)$ or squamous cell carcinoma (15.1\%). The incidence of EGFR mutations was $24 \%$. They were more common in female and younger patients ( $<60$ years). The deletion of Exon 19 and Exon 21 L858R comprised $55.1 \%$ and $31.0 \%$ of all EGFR mutations, respectively. The frequency of the T790M mutation was lower compared to that of Hispanic patients reported in the literature $(0.5 \%$ vs. $2.1 \%)$. In addition, $18.7 \%$ of the patients were positive for KRAS mutations, which was at the high end of that reported in Hispanic patients. Other driver gene alterations, ALK, MET, RET, ROS1, KRAS, ERBB2, etc., demonstrated similar incidences, as well as gender and age distributions to those previously reported. The KRAS/TP53 and KRAS/STK11 co-mutations were of very low frequencies (3.6\%), which could potentially affect the responsiveness to PD1/PD-L1 immunotherapy. Our study demonstrated that the prevalence of NSCLC gene alterations in Hispanic patients from Puerto Rico was comparable to the reported average prevalence in Latin American countries, supporting the intermediate NSCLC gene alteration rate of Hispanic patients between Asian and Caucasian patients. Novel information of the frequencies of KRAS mutation subtypes, driver gene alterations in $R O S 1, B R A F$, and $E R B B 2$, and passenger gene alterations including a rare case with the FGFR2-TACC2 translocation in Hispanic NSCLC patients from Puerto Rico were also described.
\end{abstract}


Keywords: Hispanic; Puerto Rico; NSCLC; lung cancer; gene alteration; mutation

\section{Introduction}

Cancer driver genes refer to the genes whose alterations increase cell proliferation or survival, leading to clonal expansion and tumor growth. KRAS is the first driver gene identified in lung cancer patients. It is also the most commonly mutated gene, and found in approximately $22 \%$ of the lung cancer patients in western countries [1]. To date, the driver genes identified in lung cancers include KRAS, EGFR, ALK, MET, BRAF, ROS1, RET, ERBB2, and NTRK, most of which contain actionable alterations except KRAS. The passenger genes, such as TP53, AKT1, PIK3CA, MAP2K1, STKII, KEAP1, etc. are not involved in the disease initiation, but some have a therapeutic or prognostic value. The identification of genetic alterations and specific inhibitors to these alterations has shifted the management of advanced NSCLC from surgical resection and chemotherapy to targeted therapy. Nowadays, molecular studies detecting these genetic alterations are a routine work-up in lung cancer management. These studies provide information not only for treatment, but also for prognosis and drug resistance.

The racial disparity of gene alterations in lung cancer is well known. For example, the incidence of EGFR mutations is higher in Asian patients $(\sim 40 \%)$, but lower in Caucasian patients $(\sim 11 \%)[2,3]$. Studies on the epidemiologic features of lung cancer gene alterations in Hispanic patients are relatively less and of small size except the two conducted by Arrieta et al. [4-10] in 2011 and 2015. The reported EGFR mutation rate in Hispanic patients was between Asian and Caucasian patients, widely ranging from $13 \%$ to $37.3 \%$. Hispanic patients had KRAS (7-20\%) and ALK (4.2-10.5\%) alteration rates comparable to Asian patients, but lower than Caucasian patients [6]. When breaking down the incidences of the alterations based on countries/regions, we can see a considerable variation though all the patients identified themselves as Hispanics. For example, the EGFR mutation rate is $11 \%$ in patients from Argentina, but $67 \%$ in patients from Peru. The heterogeneity of the Hispanic population is one of the reasons for this large variation. Hence, studying the epidemiologic features of lung cancer gene alterations in Hispanic patients according to the countries or regions they reside in could probably provide more valuable information than viewing them as a pure ethnic group. In this study, we analyzed the molecular genetic profiles of Hispanic NSCLC patients from Puerto Rico, presented the epidemiologic features of more than 20 genes, which expanded the current information on lung cancer gene alterations in Hispanic patients. In addition to the general characteristics, we also reported some novel findings on the incidences of KRAS mutation subgroups and passenger gene mutations, as well as KRAS/TP53 and KRAS/STKII co-mutations, which were reported to be associated with an adverse prognosis of NSCLC [11-14].

\section{Results}

\subsection{Patient Demographics and Clinical Diagnosis}

The age of the patients ranges from 35 to 95 years, with a mean age of 69 years and a median age of 70 years. Moreover, $52.7 \%$ (501/951) are male patients and $47.3 \%$ (450/951) are female patients. Of these patients, $80.3 \%$ are equal to or older than 60 years. Furthermore, $75.4 \%$ (717/951) of the patients were diagnosed with adenocarcinoma, $15.1 \%$ (144/951) of them with squamous cell carcinoma, and $6.9 \%$ (90/951) of them with other types of NSCLC (Table 1). 
Table 1. Demographic and pathologic features.

\begin{tabular}{cc}
\hline Variables & Number (\%) \\
\hline Gender & \\
Male & $501(52.7 \%)$ \\
Female & $450(47.3 \%)$ \\
Age (years) & \\
Median (range) & $70(35-95)$ \\
Mean \pm SD & $69 \pm 10.43$ \\
$<60$ years & $187(19.7 \%)$ \\
$\geq 60$ years & $764(80.3 \%)$ \\
Diagnosis & $717(75.4 \%)$ \\
Adenocarcinoma & $144(15.1 \%)$ \\
Squamous cell carcinoma & $90(9.5 \%)$ \\
Others &
\end{tabular}

\subsection{EGFR Mutation}

The EGFR status was available in $82 \%$ (780/951) of the patients. EGFR mutation(s) was identified in 24\% (187/780) of them (Table 2), with Exon 19 deletion (55.1\%, 103/187) being the most frequent one, followed by Exon 21 L858R (31.0\%, 58/187), Exon 20 insertion (4.8\%, 9/187), Exon 21 L861Q (2.7\%, 5/187), Exon 18 G719S (2.7\%, 5/187), and Exon 20 S768I (1.6\%, 3/187) (Figure S1). We compared our data with the largest NSCLC mutation study in the Hispanic/Latino population $[5,7]$ available so far (Table 2). The overall EGFR mutation rate of our patients is comparable to the reported $26.0 \%$ (1491/5738). The Exon 19 deletion had a higher rate in our patient population (55.1\% vs. $47.1 \%$, $p=0.039$ ). The frequency of Exon 21 L858R was similar to that as previously reported ( $31.0 \%$ vs. $37.3 \%$, $p=0.09)$. The combined percentage (86.1\%) of Exon 19 deletion and Exon 21 L858R was higher in our group of patients, but not significantly different from the reported $84.4 \%$ among all the EGFR mutations [5]. Exon 20 S768I had a similar frequency to that in the literature (1.6\% vs. $3.1 \%, p>0.05)$ [7]. The EGFR T790M mutation, which confers resistance to the 1st and 2nd generation tyrosine kinase inhibitors (TKIs), showed a lower rate in our study $(4 / 780,0.5 \%)$ than that reported in earlier studies $(85 / 5738,1.4 \%)(p<0.05)[5]$. EGFR mutations were detected more often in younger and female patients or patients with adenocarcinoma [2]. Our patients from Puerto Rico demonstrated a similar gender, age, and histologic predilections. Moreover, the female patients having EGFR mutations were $33.2 \%$ $(124 / 373)$ and male patients were $15.5 \%(63 / 407)(p<0.05)$. The median age of patients with positive EGFR mutation was 68 years. In patients younger than 60 years old, the mutation rate was $30.1 \%$ (46/153), higher than the $19.5 \%(80 / 410)$ found in patients older than or equal to 60 years $(p<0.05)$ (Table 3). Furthermore, the patients with adenocarcinoma having EGFR mutations were $28.2 \%(169 / 431)$, whereas only $5.4 \%$ of the patients with squamous cell carcinoma carried EGFR mutations (Table S1). The adenocarcinoma rate is significantly higher than that of squamous cell carcinoma $(p<0.05)$.

Table 2. Alteration incidences of the driver genes.

\begin{tabular}{cccc}
\hline Genes & Incidence & Reported Incidence & $p$-Value \\
\hline EGFR & $24.0 \%(187 / 780)$ & $26.0 \%(1491 / 5738)[5]$ & $p=0.2282$ \\
Exon 19 deletion & $55.1 \%(103 / 187)$ & $47.1 \%(702 / 1491)[5]$ & $p=0.0391+$ \\
Exon 21 L858R & $31.0 \%(58 / 187)$ & $37.3 \%(556 / 1491)[5]$ & $p=0.0931$ \\
Exon 20 S768I & $1.6 \%(3 / 187)$ & $3.1 \%(12 / 382)[7]$ & $p=0.2824$ \\
T790M & $0.5 \%(4 / 780)$ & $1.4 \%(85 / 5738)[5]$ & $p=0.0268+$ \\
Others & $10.2 \%(19 / 187)$ & N/A & N/A \\
KRAS & $18.7 \%(77 / 411)$ & $14.0 \%(190 / 1355)[5]$ & $p=0.0195+$ \\
ALK & $3.9 \%(28 / 710)$ & $4.2-10.5 \%[8]$ & N/A \\
ROS1 & $2.2 \%(7 / 322)$ & $0.7-3.4 \%[15]$ & N/A \\
RET & $2.1 \%(4 / 190)$ & $1.0-3.0 \%[16]$ & N/A \\
MET (Amplification) & $10.2 \%(18 / 172)$ & $2-20 \%[2,16-18]$ & N/A \\
BRAF & $4.3 \%(4 / 94)$ & $1-5 \%[19]$ & N/A \\
ERBB2 & $5.8 \%(4 / 69)$ & $2-5 \%[20]$ & N/A \\
\hline
\end{tabular}


Table 3. Gene alterations in relation to gender and age.

\begin{tabular}{|c|c|c|c|c|c|c|c|}
\hline \multirow{2}{*}{ Genes } & \multicolumn{3}{|c|}{ Gender } & \multicolumn{4}{|c|}{ Age } \\
\hline & Male & Female & $p$-Value & Median (Years) & $<60$ Years & $\geq 60$ Years & $p$-Value \\
\hline EGFR & $\begin{array}{c}15.5 \% \\
(63 / 407)\end{array}$ & $\begin{array}{c}33.2 \% \\
(124 / 373)\end{array}$ & $p<0.00001+$ & 68 & $\begin{array}{c}30.1 \% \\
(46 / 153)\end{array}$ & $\begin{array}{c}19.5 \% \\
(80 / 410)\end{array}$ & $p=0.0075+$ \\
\hline KRAS & $\begin{array}{c}21.0 \% \\
(46 / 219)\end{array}$ & $\begin{array}{c}16.1 \% \\
(31 / 193)\end{array}$ & $p=0.1991$ & 72 & $\begin{array}{l}13.5 \% \\
(10 / 74)\end{array}$ & $\begin{array}{c}29.9 \% \\
(67 / 224)\end{array}$ & $p=0.0052 \dagger$ \\
\hline$A L K$ & $\begin{array}{c}3.4 \% \\
(13 / 381)\end{array}$ & $\begin{array}{c}4.6 \% \\
(15 / 329)\end{array}$ & $p=0.4335$ & 66.5 & $\begin{array}{c}7.1 \% \\
(9 / 127)\end{array}$ & $\begin{array}{c}3.3 \% \\
(19 / 583)\end{array}$ & $p=0.0446 \dagger$ \\
\hline MET & $\begin{array}{l}7.4 \% \\
(7 / 95)\end{array}$ & $\begin{array}{l}14.3 \% \\
(11 / 77)\end{array}$ & $p=0.1406$ & 66 & $\begin{array}{l}20.0 \% \\
(5 / 25)\end{array}$ & $\begin{array}{c}8.8 \% \\
(13 / 147)\end{array}$ & $p=0.0920$ \\
\hline
\end{tabular}

\subsection{KRAS Mutation}

In our study group, the KRAS mutation rate is $18.7 \%$ (77/412), significantly higher compared to the reported frequency (14.0\%) in Hispanic patients in Arietta's paper [5] (Table 2). In contrast to the EGFR mutations, KRAS mutations occurred more often in older patients than in younger patients $(29.9 \%$ vs. $13.5 \%, p<0.05)$. The KRAS mutation rate was slightly higher in male patients, with a rate of $21 \%$ vs. $16.1 \%$ in female patients. However, this difference was not statistically significant (Table 3). A strict mutual exclusion of EGFR mutation and KRAS mutation was reported previously, but more recent studies have shown an overlap between KRAS and EGFR in a small number of cases $[16,21]$. Nine KRAS mutations have been described in the literature, with mutations in codon 12 being the most common ones. Some clinical studies demonstrated that G12V and G12C mutations were associated with poor prognosis [13,14]. In addition, codon 12 mutations were detected in $97.4 \%$ (75/77) of our patients, and the frequencies of particular codon 12 mutations were as follows: G12C (40.3\%), G12V (18.2\%), G12D (23.4\%), and G12A (6.5\%) (Table 4). The co-existence of KRAS mutations with secondary mutations has been reported to have some distinctive clinical features, e.g., KRAS and STK11 co-mutations are associated with poor overall survival, and patients with concurrent KRAS and p53 mutations are more sensitive to PD1 and PD-L1 immunotherapy [11,12]. In our patients from Puerto Rico, the co-mutations of KRAS/p53 or KRAS/STK11 were 3.6\% (2/55) for each combination (Table 4).

Table 4. KRAS mutation subtypes and co-mutations.

\begin{tabular}{cc}
\hline Gene Mutations & Percentage \\
\hline KRAS & \\
Condon 12 & $97.4 \%(75 / 77)$ \\
G12C & $40.3 \%(31 / 77)$ \\
G12V & $18.2 \%(14 / 77)$ \\
G12D & $23.4 \%(18 / 77)$ \\
G12A & $6.5 \%(5 / 77)$ \\
KRAS + TP53 & $3.6 \%(2 / 55)$ \\
KRAS + STK11 & $3.6 \%(2 / 55)$ \\
\hline
\end{tabular}

\subsection{ALK Rearrangement}

The $A L K$ rearrangement is a targetable genetic alteration in NSCLC with a low incidence. The reported ALK rearrangement rates in Caucasian, Asian, and Hispanic patients are 1-3\%, 2.3-6.7\%, and $4.2-10.5 \%$, respectively [8]. In our study, the frequency of $A L K$ rearrangement was $3.9 \%$ as detected by FISH (28/710) (Table 2). This is within the range of the $A L K$ rearrangement rate of Asian patients. The $A L K$ rearrangement tends to be present in younger patients, with a median age of 52 years [22]. In our study cohort, the median age of patients with a positive $A L K$ rearrangement was 66.5 years, but it occurred more frequently in relatively young patients, with a rearrangement rate of $7.1 \%(9 / 127)$ in patients 
younger than 60 years and 3.3\% (19/583) in patients older than 60 years $(p<0.05)$ (Table 3). Though the incidence of $A L K$ rearrangement is reported to have a male predilection [22], we did not see this gender difference in our study (Table 3).

\subsection{MET Amplification and Mutation}

The MET gene amplification, mutation, rearrangement, and protein overexpression all lead to an elevated MET protein kinase activity and tumor growth [23]. A secondary MET amplification also plays a role in acquired TKI resistance [24]. The MET gene amplification is now used as a biomarker to predict the responsiveness to MET inhibitors. In TKI-naïve NSCLC, the incidence of MET amplification ranges from $2-5 \%$, and reaches $5-20 \%$ in NSCLC with resistance to the 1 st or 2 nd generation of TKIs [2,16-18]. An increased MET amplification ( $\geq 5 \mathrm{GCN}$ ) is an adverse prognostic factor in surgically resected NSCLC [25]. We have tested 172 patients for MET amplification by FISH, 10.5\% (18/172) of them had increased MET gene copy numbers (Table 3). The median age of MET amplification patients was 66 years. No age or gender predilection is observed. In the 69 patients tested with NGS results (different from the 172 patients above), five patients carried MET mutations, but none of the mutations have a definite clinical significance (Table S2). The bioinformatics analysis revealed that these mutations have no potential to lead the MET Exon 14 skipping.

\subsection{Other Driver Gene Alterations}

In our study, $2.2 \%$ of the patients had the ROS1 positive rearrangement (7/322), similar to the reported $0.7-3.4 \%$ [15]. In addition, $2.1 \%$ of the patients had the RET positive rearrangement (4/190), similar to the reported 1.0-3.0\% [16]. A total of 94 patients had BRAF tested by NGS and four of them were positive (4.3\%), which is also comparable to the reported 1-5\% in non-ethnic based studies [19]. $E R B B 2$ was detected by NGS with four positives $(6 \%, 4 / 69)$, similar to the documented $2-5 \%$ in lung adenocarcinoma (Table 2) [20].

\subsection{Overlaps of Driver Gene Alterations}

Recent publications have reported overlaps of driver mutations though at a very low rate [26,27], and our data supported these observations. Among the driver genes, $B R A F$ is the only one showing no overlap with others. We observed two cases with overlapping KRAS and EGFR mutations, both co-existed with Exon 19 deletion. ALK, ROS1, RET, and MET each coexist with EGFR in a few cases, KRAS coexisted with MET in two patients, and ROS1 and RET were both positive in one patient (Figure S2).

\subsection{Passenger Gene Alterations}

Passenger gene alterations were tested in 55 patients by NGS (Table S3). TP53 had the highest mutation rate, $54.55 \%$ (30/55). The incidences of mutations in other genes, such as STK11, IGF1, FGFR, etc., ranged from $0 \%$ to $11.24 \%$ (Table 5). A very interesting finding is that one of the two cases with FGFR2 gene alterations harbored the FGFR2-TACC2 translocation. The patient was an 85-year-old female with a mucinous adenocarcinoma of the lung. 
Table 5. Frequencies of passenger gene alterations.

\begin{tabular}{cccc}
\hline Genes & Positive (n) & Tested (n) & Percentage (\%) \\
\hline TP53 & 30 & 55 & 54.6 \\
STK11 & 6 & 55 & 10.9 \\
FGFR1 & 6 & 55 & 10.9 \\
PIK3CA & 5 & 55 & 9.1 \\
IGF1 & 5 & 55 & 9.1 \\
DDR2 & 4 & 55 & 7.3 \\
MDM2 & 3 & 55 & 5.5 \\
PTEN & 2 & 55 & 3.6 \\
FGFR2 & 2 \# & 55 & 3.6 \\
FGFR3 & 2 & 55 & 3.6 \\
HRAS & 1 & 55 & 1.8 \\
PDGFRA & 1 & 55 & 1.8 \\
BCL2 & 1 & 55 & 1.8 \\
AKT1 & 0 & 55 & 0 \\
ARAF & 0 & 55 & 0 \\
MAP2K1 & 0 & 55 & 0 \\
\hline \multicolumn{4}{l}{ \#: One case with the FGFR2-TACC2 fusion. }
\end{tabular}

\section{Discussion}

EGFR mutations in NSCLC have a strong racial disparity: More common in Asian patients $(40-51.4 \%)$ than Caucasian patients $(9.8-11 \%)$ [2,3]. The data on the Hispanic population vary over a wide range. Some of the studies demonstrated that the incidences are between Asian and Caucasian patients, ranging from 24.6-35.3\% [5,7,8]. Others showed lower EGFR frequencies (13-18\%) and no difference from that seen in Caucasian patients [4,8-10]. The EGFR mutation rate of patients from Puerto Rico in our study was $24.0 \%$, consistent with the intermediate EGFR mutation rate in Hispanic NSCLC patients. The Exon 19 deletion and Exon 21 L858R mutation are the two most common EGFR mutations, comprising 85-90\% of all the EGFR mutations, with Exon 19 deletion slightly more common than Exon 21 L858R [2]. These two mutations are associated with a better prognosis regardless of the treatment [2]. The frequency of Exon 19 deletion in our study was higher than the reported incidence in Arrieta's paper (55.1\% vs. $47.1 \%)(p<0.05)$, and the Exon 21 L858R mutation rate was relatively lower but with no significant difference $(31.0 \%$ vs. $37.3 \%, p>0.05)$. The combined incidence of Exon 19 deletion and Exon 21 L858R mutation (86.1\%) was comparable to that published in the literature. There is no difference between the Exon 19 deletion and Exon 21 L858R mutation regarding their responsiveness to therapy or disease prognosis. Therefore, the above difference may not be clinically significant. The EGFR T790M mutation is one of the mechanisms for the tyrosine kinase inhibitor (TKI) resistance. It can either occur as a primary mutation or as an acquired mutation following the TKI treatment. The T790M mutation can be as high as $\sim 50 \%$ in patients treated with TKIs, whereas the treatment-naive mutations are reported to be less than $1 \%[28,29]$. This mutation almost always coexists with either the Exon 19 deletion or the L858R mutation. The Exon 19 deletions are more commonly present with the acquired T790M but the L858R is more likely with the primary T790M [28]. In our study, out of 780 patients with positive EGFR mutations, only four of them $(0.4 \%)$ have a concomitant T790M, which is within the range of the reported incidence of primary T790M. All the four cases had the Exon 19 deletion. Due to the lack of treatment information, we were not able to determine whether the T790M mutations were primary or acquired. The best interpretation of this low occurrence could be the low prevalence of TKI use in our study population.

Globally, KRAS mutations are the most common mutations in NSCLC and considered a negative prognostic factor [30]. Asian patients have a lower KRAS mutation rate (8-15\%) compared to patients from western countries (18-28.1\%) [13,31,32]. The frequencies of KRAS mutations in Hispanic/Latino patients are reported between $7-20$, comparable to that in the Asian population $[5,6,8,33,34]$. In our study cohort the KRAS mutation rate was $18.7 \%$. This mutation rate falls into the reported range of 
Hispanic patients but is significantly higher than that reported in the Arietta's paper [5]. Most KRAS mutations were located at codons 12,13, and 61. Some mutation subtypes are associated with an adverse prognosis. G12V and G12C portend an inferior overall survival compared to the G12A and G12D mutations $[13,14]$. In our study, $97.4 \%$ of the patients had codon 12 mutations $(75 / 77)$, and the frequencies of individual mutations were as follows: G12C (40.3\%), G12V (18.2\%), G12D (23.4\%), and G12A (6.5\%). G12V and G12C combined constitute 58.4\% (45/77) of all KRAS mutations, and G12A and G12D account for 29.9\% (23/77). These numbers were similar to the reported values: G12C (39\%), G12V (18-21\%), G12D (17-18\%), and G12A (10.8\%) [13,14].

Though the development of specific inhibitors to KRAS or its downstream signaling molecules has been a difficult journey without success so far, recent studies show that the KRAS co-mutation status in NSCLC is associated with its responsiveness to the PD-1/PD-L1 immunotherapy, as well as the disease prognosis [34]. Lung adenocarcinomas with concurrent KRAS and TP53 mutations are more responsive to PD1/PD-L1 inhibitors, whereas tumors with KRAS and STKII co-mutations exhibit resistance to those inhibitors [11,12]. Patients with KRAS and STKII co-mutations or with the STKII mutation alone also have poor overall survival compared to patients with no concurrent mutations, wild type KRAS, or wild type STKII [12]. Our study cohort included 55 patients with available KRAS, TP53, and STKII mutation statuses available for analysis. Our current observation is the first study reporting data of concurrent KRAS/TP53 and KRAS/STKII mutations in the Hispanic population. Surprisingly, these concurrent mutations in Hispanic NSCLC from Puerto Rico were very rare; only two cases for each combination (3.6\%), compared to the published data (52\% and 18\%, respectively) [14]. Therefore, in Puerto Rican patients, the KRAS co-mutation status may not be a proper biomarker to estimate the responsiveness to immunotherapy. Moreover, the rarity of these co-mutations in Puerto Rican patients makes them an unfavorable population for studying these co-mutations. The low incidences cannot be explained by each individual frequency of KRAS, TP53, and STK11 mutations. The KRAS mutation frequency was relatively lower (18.7 vs. 27\%) in our study [14], but the frequencies of STK11 and TP53 mutations were similar to the reported values (11\% vs. $8-18 \%$ for STK11; $55 \%$ vs. $46 \%$ for TP53) $[16,35,36]$.

The chromosomal translocation joining in-frame members of the fibroblast growth factor receptor-transforming acidic coiled-coil gene families (FGFR-TACC gene fusions) were first identified in a human glioblastoma multiforme [37]. The most common fusion type is FGFR3-TACC3, which has been discovered in many cancer types including lung cancer. The fusion between FGFR and TACC genes results in a constitutively activated kinase, which induces mitotic and chromosomal segregation defects, subsequently triggering aneuploidy. Clinical data showed promising effects of FGFR inhibitors in malignant tumors harboring FGFR-TACC fusions [37-39]. The rearrangement involving FGFR2-TACC2 had never been reported in lung cancer before. Our study identified a novel actionable rearrangement involving FGFR2-TACC2 in one of 55 patients tested by NGS. Figure 1 diagrams the predicted protein structure of the FGFR2-TACC2 fusion from this patient. The patient presented with mucinous adenocarcinoma of the lung. Interestingly, there is another report of a FGFR2-TACC2 translocation identified in a mucinous stomach adenocarcinoma in The Cancer Genome Atlas (TCGA) PanCancer studies (TCGA-BR-8080-01). The findings warrant further investigation of the FGFR2-TACC2 translocation in mucinous adenocarcinoma from different origins.

To the best of our knowledge, our study cohort is the first study on the frequencies of KRAS mutation subtypes, driver gene ROS1 rearrangement, drive gene $B R A F$ and $E R B B 2$ mutations, and passenger gene alterations including the FGFR2-TACC2 translocation in Hispanic NSCLC patients. 
A)
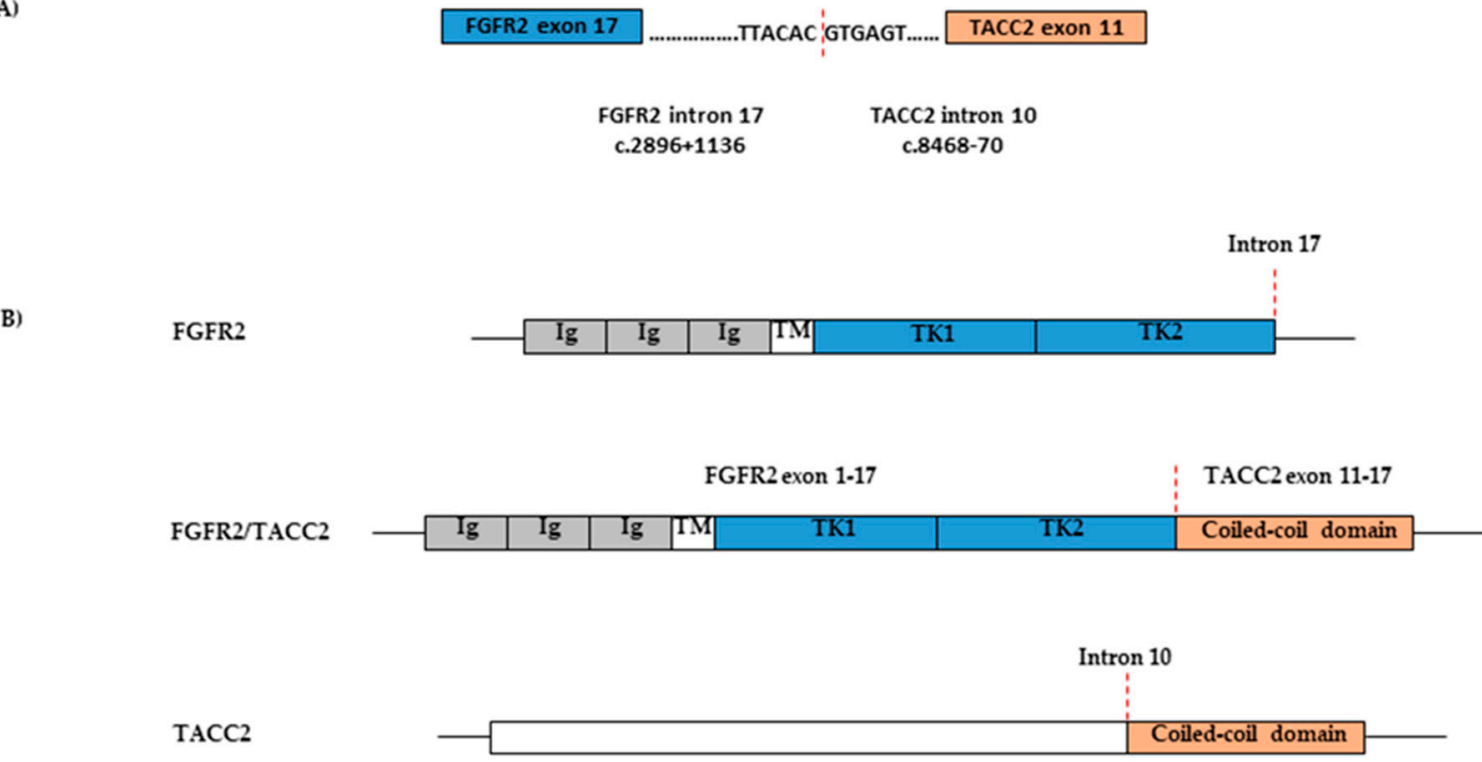

Figure 1. Predicted protein structure of FGFR2-TACC2 fusion. (A) Sequence of the region fused between FGFR2 and TACC2 in genome. (B) Schematic of FGFR2-TACC2 fusion involving exons 1 to 17 of FGFR2 and exons 11 to 17 of TACC2. Red dashed lines indicate breakpoints. FGFR2, fibroblast growth factor receptor 2; TACC2, transforming acidic coiled-coil-containing protein 2; $\mathrm{Ig}$, disulfide linked immunoglobin-like domains; TM, transmembrane domain; TK, intracellular tyrosine kinase domain.

\section{Materials and Methods}

\subsection{Patients}

We conducted a retrospective study of lung cancer gene alterations in Hispanic NSCLC patients from Puerto Rico, who had lung cancer molecular tests performed between 2011 and 2018, in the Genoptix Medical Laboratory in Carlsbad, CA, USA. The diagnosis of NSCLC is based on the information on the requisition forms provided by the requesting clinicians. The specimens were submitted to the Genoptix Medical Laboratory randomly from twenty medical centers or doctor offices across the whole territory of Puerto Rico. The IRB approval (ID: 6173) to perform a retrospective chart review to collect and analyze clinical data, including laboratory, FISH, mutational, demographic, and pathological data, was issued by the Sterling IRB ethic committee on 11 December 2017.

\subsection{Next Generation Sequencing}

The Lung NGS panel (amplicon-based, targeted) of 25 genes was conducted on an Illumina MidiSeq instrument using genomic DNA isolated from unstained FFPE slides. The targeted genes include AKT1, ALK, ARAF, BCL2, BRAF, DDR2, EGFR, ERBB2, FGFR1, FGFR2, FGFR3, HRAS, IGF1, KRAS, MAP2K, MDM2, MET, NRAS, PDGFRA, PIK3CA, PTEN, RET, ROS1, STK11, TP53. The alterations within each of those genes were analyzed through the proprietary bioinformatic software and interpreted in conjunction with reference databases such as COSMIC and dbSNP. Quality control metrics included a minimum input of $20 \mathrm{ng}$, with an optimal input of $100 \mathrm{ng}$ of genomic DNA and average mean sequencing depth of $500 \times$ coverage. The limits of detection (LOD) were $5 \%$ for SNV, $10 \%$ for Indels, $\geq 6$ copies for gene amplifications, and $\leq 0.3$ copies for homozygous gene deletions. Insertions greater than 15 nucleotides and deletions greater than 52 nucleotides may not be detected. Benign sequence variants were not reported. 


\subsection{Multiplex PCR}

Mutations of EGFR, KRAS, and BRAF were detected using multiplex PCR, including Exon 19 deletion, Exon 20 insertion, L858R, S786I, G719X, L861Q, and T790M for EGFR, mutations in codon 12, 13 , and 61 for $K R A S$, and V600E for BRAF.

\subsection{FISH}

Gene rearrangements of $A L K, R O S 1$, and RET were detected on unstained FFPE slides by a fluorescent break apart (BA) DNA probes and gene amplification of MET was detected on unstained FFPE slides by fluorescent MET and CEP7 DNA probes. Fifty cells for ALK or sixty cells for MET, ROS1, and RET were analyzed for each case. Accordingly, 15\% or more of the tumor cells showing split signals of the fluorescent probes was considered positive (Figure S3). Based on the MET-CN and MET/CEP7 ratio, the patients' MET results were classified as an MET-amplification: MET/CEP7 $\geq 2$ or $M E T-C N \geq 5$. Fusion partners could not be identified in these FISH assays with break apart DNA probes.

\subsection{Statistical Analysis}

The categorical variables in this study were analyzed using the $\chi^{2}$ test and $p<0.05$ was considered statistically significant.

\section{Conclusions}

In summary, targeted therapy is the trend of medicine. Understanding the epidemiologic features of the genetic alterations in NSCLC in different racial groups improves the efficacy and predictability of the treatment. Our data indicate that Hispanic patients from Puerto Rico showed an intermediate rate of EGFR mutations and $A L K$ rearrangements, similar to that in most Latin American countries. The KRAS mutation rate was at the high end of the reported frequencies in the Hispanic patients, and close to the rate of Caucasian patients. The frequencies of $K R A S$ mutation subtypes, driver gene alterations in $R O S 1, B R A F$, and $E R B B 2$, and passenger gene alterations including a rare case with the FGFR2-TACC2 translocation are novel information in this racial group, which need confirmation by other independent studies.

Supplementary Materials: The following are available online at http://www.mdpi.com/2072-6694/12/12/3492/s1. Table S1: EGFR mutations in different histologic types; Table S2: MET mutations detected by NGS; Table S3: Clinical data of 55 patients with passenger gene mutations; Figure S1: EGFR mutation composition; Figure S2: Overlap of driver gene alterations; Figure S3: Representative FISH figures.

Author Contributions: Conceptualization, J.-G.J.; methodology and formal analysis, R.Z., Z.Y., B.Y., A.S.J. and J.-G.J.; writing—original draft preparation, R.Z., Z.Y., and A.A.; writing—review and editing, J.-G.J., Q.W., Z.J., D.L. (Dongfang Liu), and S.A.; supervision, J.-G.J.; project administration, J.-G.J. and D.L. (Derek Lyle). All authors have read and agreed to the published version of the manuscript.

Funding: This research received no external funding.

Acknowledgments: The authors thank Paris Petersen in the Genoptix Medical Laboratory for searching and collecting data for this study.

Conflicts of Interest: The authors declare no conflict of interest.

\section{References}

1. Karachaliou, N.; Mayo, C.; Costa, C.; Magri, I.; Gimenez-Capitan, A.; Molina-Vila, M.A.; Rosell, R. KRAS mutations in lung cancer. Clin. Lung Cancer 2013, 14, 205-214. [CrossRef] [PubMed]

2. Da Cunha Santos, G.; Shepherd, F.A.; Tsao, M.S. EGFR mutations and lung cancer. Annu. Rev. Pathol. 2011, 6, 49-69. [CrossRef] [PubMed]

3. Gahr, S.; Stoehr, R.; Geissinger, E.; Ficker, J.H.; Brueckl, W.M.; Gschwendtner, A.; Gattenloehner, S.; Fuchs, F.S.; Schulz, C.; Rieker, R.J.; et al. EGFR mutational status in a large series of Caucasian European NSCLC patients: Data from daily practice. Br. J. Cancer 2013, 109, 1821-1828. [CrossRef] [PubMed] 
4. Zhang, W.; McQuitty, E.B.; Olsen, R.; Fan, H.; Hendrickson, H.; Tio, F.O.; Newton, K.; Cagle, P.T.; Jagirdar, J. EGFR mutations in US Hispanic versus non-Hispanic white patients with lung adenocarcinoma. Arch. Pathol. Lab. Med. 2014, 138, 543-545. [CrossRef] [PubMed]

5. Arrieta, O.; Cardona, A.F.; Martin, C.; Mas-Lopez, L.; Corrales-Rodriguez, L.; Bramuglia, G.; Castillo-Fernandez, O.; Meyerson, M.; Amieva-Rivera, E.; Campos-Parra, A.D.; et al. Updated Frequency of EGFR and KRAS Mutations in NonSmall-Cell Lung Cancer in Latin America: The Latin-American Consortium for the Investigation of Lung Cancer (CLICaP). J. Thorac. Oncol. 2015, 10, 838-843. [CrossRef] [PubMed]

6. Gimbrone, N.T.; Sarcar, B.; Gordian, E.R.; Rivera, J.I.; Lopez, C.; Yoder, S.J.; Teer, J.K.; Welsh, E.A.; Chiappori, A.A.; Schabath, M.B.; et al. Somatic Mutations and Ancestry Markers in Hispanic Lung Cancer Patients. J. Thorac. Oncol. 2017, 12, 1851-1856. [CrossRef]

7. Arrieta, O.; Cardona, A.F.; Federico Bramuglia, G.; Gallo, A.; Campos-Parra, A.D.; Serrano, S.; Castro, M.; Aviles, A.; Amorin, E.; Kirchuk, R.; et al. Genotyping non-small cell lung cancer (NSCLC) in Latin America. J. Thorac. Oncol. 2011, 6, 1955-1959. [CrossRef]

8. Cress, W.D.; Chiappori, A.; Santiago, P.; Munoz-Antonia, T. Lung cancer mutations and use of targeted agents in Hispanics. Rev. Recent. Clin. Trials 2014, 9, 225-232. [CrossRef]

9. Cortes-Funes, H.; Gomez, C.; Rosell, R.; Valero, P.; Garcia-Giron, C.; Velasco, A.; Izquierdo, A.; Diz, P.; Camps, C.; Castellanos, D.; et al. Epidermal growth factor receptor activating mutations in Spanish gefitinib-treated non-small-cell lung cancer patients. Ann. Oncol. 2005, 16, 1081-1086. [CrossRef]

10. Lopez-Chavez, A.; Thomas, A.; Evbuomwan, M.O.; Xi, L.; Chun, G.; Vidaurre, T.; Arrieta, O.; Oblitas, G., 3rd; Oton, A.B.; Calvo, A.R.; et al. EGFR Mutations in Latinos from the United States and Latin America. J. Glob. Oncol. 2016, 2, 259-267. [CrossRef]

11. Dong, Z.Y.; Zhong, W.Z.; Zhang, X.C.; Su, J.; Xie, Z.; Liu, S.Y.; Tu, H.Y.; Chen, H.J.; Sun, Y.L.; Zhou, Q.; et al. Potential Predictive Value of TP53 and KRAS Mutation Status for Response to PD-1 Blockade Immunotherapy in Lung Adenocarcinoma. Clin. Cancer Res. 2017, 23, 3012-3024. [CrossRef] [PubMed]

12. Skoulidis, F.; Goldberg, M.E.; Greenawalt, D.M.; Hellmann, M.D.; Awad, M.M.; Gainor, J.F.; Schrock, A.B.; Hartmaier, R.J.; Trabucco, S.E.; Gay, L.; et al. STK11/LKB1 Mutations and PD-1 Inhibitor Resistance in KRAS-Mutant Lung Adenocarcinoma. Cancer Discov. 2018, 8, 822-835. [CrossRef] [PubMed]

13. Dogan, S.; Shen, R.; Ang, D.C.; Johnson, M.L.; D’Angelo, S.P.; Paik, P.K.; Brzostowski, E.B.; Riely, G.J.; Kris, M.G.; Zakowski, M.F.; et al. Molecular epidemiology of EGFR and KRAS mutations in 3026 lung adenocarcinomas: Higher susceptibility of women to smoking-related KRAS-mutant cancers. Clin. Cancer Res. 2012, 18, 6169-6177. [CrossRef] [PubMed]

14. El Osta, B.; Behera, M.; Kim, S.; Berry, L.D.; Sica, G.; Pillai, R.N.; Owonikoko, T.K.; Kris, M.G.; Johnson, B.E.; Kwiatkowski, D.J.; et al. Characteristics and Outcomes of Patients with Metastatic KRAS-Mutant Lung Adenocarcinomas: The Lung Cancer Mutation Consortium Experience. J. Thorac. Oncol. 2019, 14, 876-889. [CrossRef] [PubMed]

15. Bubendorf, L.; Buttner, R.; Al-Dayel, F.; Dietel, M.; Elmberger, G.; Kerr, K.; Lopez-Rios, F.; Marchetti, A.; Oz, B.; Pauwels, P.; et al. Testing for ROS1 in non-small cell lung cancer: A review with recommendations. Virchows Arch. 2016, 469, 489-503. [CrossRef] [PubMed]

16. Cancer Genome Atlas Research, N. Comprehensive molecular profiling of lung adenocarcinoma. Nature 2014, 511, 543-550. [CrossRef]

17. Sterlacci, W.; Fiegl, M.; Gugger, M.; Bubendorf, L.; Savic, S.; Tzankov, A. MET overexpression and gene amplification: Prevalence, clinico-pathological characteristics and prognostic significance in a large cohort of patients with surgically resected NSCLC. Virchows Arch. 2017, 471, 49-55. [CrossRef]

18. Yu, H.A.; Arcila, M.E.; Rekhtman, N.; Sima, C.S.; Zakowski, M.F.; Pao, W.; Kris, M.G.; Miller, V.A.; Ladanyi, M.; Riely, G.J. Analysis of tumor specimens at the time of acquired resistance to EGFR-TKI therapy in 155 patients with EGFR-mutant lung cancers. Clin. Cancer Res. 2013, 19, 2240-2247. [CrossRef] [PubMed]

19. O'Leary, C.G.; Andelkovic, V.; Ladwa, R.; Pavlakis, N.; Zhou, C.; Hirsch, F.; Richard, D.; O’Byrne, K. Targeting BRAF mutations in non-small cell lung cancer. Transl. Lung Cancer Res. 2019, 8, 1119-1124. [CrossRef] [PubMed] 
20. Garrido-Castro, A.C.; Felip, E. HER2 driven non-small cell lung cancer (NSCLC): Potential therapeutic approaches. Transl. Lung Cancer Res. 2013, 2, 122-127. [CrossRef]

21. Gainor, J.F.; Varghese, A.M.; Ou, S.H.; Kabraji, S.; Awad, M.M.; Katayama, R.; Pawlak, A.; Mino-Kenudson, M.; Yeap, B.Y.; Riely, G.J.; et al. ALK rearrangements are mutually exclusive with mutations in EGFR or KRAS: An analysis of 1,683 patients with non-small cell lung cancer. Clin. Cancer Res. 2013, 19, 4273-4281. [CrossRef]

22. Chia, P.L.; Mitchell, P.; Dobrovic, A.; John, T. Prevalence and natural history of ALK positive non-small-cell lung cancer and the clinical impact of targeted therapy with ALK inhibitors. Clin. Epidemiol. 2014, 6, 423-432. [CrossRef]

23. Salgia, R. MET in Lung Cancer: Biomarker Selection Based on Scientific Rationale. Mol. Cancer Ther. 2017, 16, 555-565. [CrossRef]

24. Wang, Q.; Yang, S.; Wang, K.; Sun, S.Y. MET inhibitors for targeted therapy of EGFR TKI-resistant lung cancer. J. Hematol. Oncol. 2019, 12, 63. [CrossRef]

25. Cappuzzo, F.; Marchetti, A.; Skokan, M.; Rossi, E.; Gajapathy, S.; Felicioni, L.; Del Grammastro, M.; Sciarrotta, M.G.; Buttitta, F.; Incarbone, M.; et al. Increased MET gene copy number negatively affects survival of surgically resected non-small-cell lung cancer patients. J. Clin. Oncol. 2009, 27, 1667-1674. [CrossRef] [PubMed]

26. Sweis, R.F.; Thomas, S.; Bank, B.; Fishkin, P.; Mooney, C.; Salgia, R. Concurrent EGFR Mutation and ALK Translocation in Non-Small Cell Lung Cancer. Cureus 2016, 8, e513. [CrossRef]

27. Lee, T.; Lee, B.; Choi, Y.L.; Han, J.; Ahn, M.J.; Um, S.W. Non-small Cell Lung Cancer with Concomitant EGFR, KRAS, and ALK Mutation: Clinicopathologic Features of 12 Cases. J. Pathol. Transl. Med. 2016, 50, 197-203. [CrossRef]

28. Li, W.; Qiu, T.; Guo, L.; Ling, Y.; Gao, Y.; Ying, J.; He, J. Primary and acquired EGFR T790M-mutant NSCLC patients identified by routine mutation testing show different characteristics but may both respond to osimertinib treatment. Cancer Lett. 2018, 423, 9-15. [CrossRef]

29. Assi, H.; Tfayli, A.; Assaf, N.; Daya, S.A.; Bidikian, A.H.; Kawsarani, D.; Fermanian, P.; Zaatari, G.; Mahfouz, R. Prevalence of T790M mutation among TKI-therapy resistant Lebanese lung cancer patients based on liquid biopsy analysis: A first report from a major tertiary care center. Mol. Biol. Rep. 2019, 46, 3671-3676. [CrossRef]

30. Roman, M.; Baraibar, I.; Lopez, I.; Nadal, E.; Rolfo, C.; Vicent, S.; Gil-Bazo, I. KRAS oncogene in non-small cell lung cancer: Clinical perspectives on the treatment of an old target. Mol. Cancer 2018, 17, 33. [CrossRef]

31. Cai, D.; Hu, C.; Li, L.; Deng, S.; Yang, J.; Han-Zhang, H.; Li, M. The prevalence and prognostic value of KRAS co-mutation subtypes in Chinese advanced non-small cell lung cancer patients. Cancer Med. 2020, 9, 84-93. [CrossRef] [PubMed]

32. Soh, J.; Toyooka, S.; Matsuo, K.; Yamamoto, H.; Wistuba, I.I.; Lam, S.; Fong, K.M.; Gazdar, A.F.; Miyoshi, S. Ethnicity affects EGFR and KRAS gene alterations of lung adenocarcinoma. Oncol. Lett. 2015, 10, 1775-1782. [CrossRef] [PubMed]

33. Reinersman, J.M.; Johnson, M.L.; Riely, G.J.; Chitale, D.A.; Nicastri, A.D.; Soff, G.A.; Schwartz, A.G.; Sima, C.S.; Ayalew, G.; Lau, C.; et al. Frequency of EGFR and KRAS mutations in lung adenocarcinomas in African Americans. J. Thorac. Oncol. 2011, 6, 28-31. [CrossRef] [PubMed]

34. Ferrer, I.; Zugazagoitia, J.; Herbertz, S.; John, W.; Paz-Ares, L.; Schmid-Bindert, G. KRAS-Mutant non-small cell lung cancer: From biology to therapy. Lung Cancer 2018, 124, 53-64. [CrossRef] [PubMed]

35. Facchinetti, F.; Bluthgen, M.V.; Tergemina-Clain, G.; Faivre, L.; Pignon, J.P.; Planchard, D.; Remon, J.; Soria, J.C.; Lacroix, L.; Besse, B. LKB1/STK11 mutations in non-small cell lung cancer patients: Descriptive analysis and prognostic value. Lung Cancer 2017, 112, 62-68. [CrossRef] [PubMed]

36. Ding, L.; Getz, G.; Wheeler, D.A.; Mardis, E.R.; McLellan, M.D.; Cibulskis, K.; Sougnez, C.; Greulich, H.; Muzny, D.M.; Morgan, M.B.; et al. Somatic mutations affect key pathways in lung adenocarcinoma. Nature 2008, 455, 1069-1075. [CrossRef]

37. Lasorella, A.; Sanson, M.; Iavarone, A. FGFR-TACC gene fusions in human glioma. Neuro Oncol. 2017, 19, 475-483. [CrossRef] 
38. Helsten, T.; Elkin, S.; Arthur, E.; Tomson, B.N.; Carter, J.; Kurzrock, R. The FGFR landscape in cancer: Analysis of 4,853 tumors by next-generation sequencing. Clin. Cancer Res. 2016, 22, 259-267. [CrossRef]

39. Sun, X.; Zuo, K.; Yao, Q.; Zhou, S.; Shui, R.; Xu, X.; Bi, R.; Yu, B.; Cheng, Y.; Tu, X.; et al. Invasive apocrine carcinoma of the breast: Clinicopathologic features and comprehensive genomic profiling of 18 pure triple-negative apocrine carcinomas. Mod. Pathol. 2020. [CrossRef]

Publisher's Note: MDPI stays neutral with regard to jurisdictional claims in published maps and institutional affiliations.

(C) 2020 by the authors. Licensee MDPI, Basel, Switzerland. This article is an open access article distributed under the terms and conditions of the Creative Commons Attribution (CC BY) license (http://creativecommons.org/licenses/by/4.0/). 